\title{
Endometritis decreases the population of uterine neurons in the paracervical ganglion and changes the expression of sympathetic neurotransmitters in sexually mature gilts
}

Bartosz Miciński $i^{*}$, Barbara Jana ${ }^{2^{*}}$ and Jarosław Całka ${ }^{1}$

\begin{abstract}
Background: The focus of the study was to examine the impact of the inflamed uterus on the population of the paracervical ganglion (PCG) uterus-innervating perikarya and their chemical coding. Fast Blue retrograde tracer was injected into the wall of uterine horns on the 17th day of the first studied estrous cycle. After 28 days, either Escherichia coli suspension or saline was applied to the horns of the uterus, whereas the control group received laparotomy only. Eight days after the above-mentioned procedures, uterine cervices with PCG were collected. Both macroscopic and histopathologic examinations confirmed severe acute endometritis in the Escherichia coli-injected uteri. The double immunofluorescence method was used to analyze changes in the PCG populations coded with dopamine- $\beta$-hydroxylase $(D \beta H)$ and/or neuropeptide $Y(N P Y)$, somatostatin $(S O M)$, vasoactive intestinal polypeptide (VIP) and neuronal isoform of nitric oxide synthase (nNOS).
\end{abstract}

Results: The use of Escherichia coli lowered the total number of Fast Blue-positive neurons. Moreover, an increase in $\mathrm{D} \beta \mathrm{H}+\mathrm{NIP}+, \mathrm{D} \beta \mathrm{H}+/ \mathrm{NPY}+, \mathrm{D} \beta \mathrm{H}+/ \mathrm{SOM}+$ and $\mathrm{D} \beta \mathrm{H}+/ \mathrm{nNOS}+$ expressing perikarya was noted. A rise in nonnoradrenergic VIP-, SOM- and nNOS-immunopositive populations was also recorded, as well as a drop in D $\mathrm{BH}$ positive neurotransmitter-negative neurons.

Conclusions: To sum up, inflammation of the uterus has an impact on the neurochemical properties of the uterine perikarya in PCG, possibly affecting the functions of the organ.

Keywords: Autonomic nervous system, Chemical coding, Pig, Endometritis, Immunocytochemistry

\footnotetext{
* Correspondence: bartosz.micinski@uwm.edu.pl; b.jana@pan.olsztyn.pl

'Department of Clinical Physiology, Faculty of Veterinary Medicine, University of Warmia and Mazury, Oczapowskiego 13, 10-719 Olsztyn, Poland

${ }^{2}$ Division of Reproductive Biology, Institute of Animal Reproduction and Food Research, Polish Academy of Sciences, Tuwima 10, 10-748 Olsztyn, Poland
}

(c) The Author(s). 2021 Open Access This article is licensed under a Creative Commons Attribution 4.0 International License, which permits use, sharing, adaptation, distribution and reproduction in any medium or format, as long as you give appropriate credit to the original author(s) and the source, provide a link to the Creative Commons licence, and indicate if changes were made. The images or other third party material in this article are included in the article's Creative Commons licence, unless indicated otherwise in a credit line to the material. If material is not included in the article's Creative Commons licence and your intended use is not permitted by statutory regulation or exceeds the permitted use, you will need to obtain permission directly from the copyright holder. To view a copy of this licence, visit http://creativecommons.org/licenses/by/4.0/. The Creative Commons Public Domain Dedication waiver (http://creativecommons.org/publicdomain/zero/1.0/) applies to the data made available in this article, unless otherwise stated in a credit line to the data. 


\section{Background}

One of the most common pathologic conditions in domestic animals generating severe economic problems for breeders, such as increased medical costs and deteriorated reproductive indicators, is uterus inflammation. This disease develops in response to non-infectious agents and, more importantly, to bacteriological factors. Mainly occurring after parturition, metritis/endometritis might also be evoked through natural mating or insemination in primiparous animals [1-3]. Its mechanism is based on the problems with uterine involution, often matched with immunological reaction, which consists of an increase in the levels of proinflammatory cytokines and other mediators, including tumor necrosis factor- $\alpha$, interleukins - IL-1 $\beta$, IL-6, IL-8, nitric oxide (NO), prostaglandins - PGF2 $\alpha$, PGE2, as well as leukotrienes LTB4 and LTC4 [4-6].

The paracervical ganglion (PCG; Frankenhauser's ganglion) is an unprecedented formation belonging to the autonomic nervous system. It contains both sympathetic (noradrenergic) as well as a parasympathetic (cholinergic) component and is a part of a larger pelvic plexus innervating organs of the urinary tract and reproductive system [7-9]. The porcine uterus is supplied by nerve terminals from many autonomic and sensory ganglia including the PCG. This has been confirmed in the past with the use of Fast Blue (FB) fluorescent retrograde neuronal tracer, which indicated the existence of uterusinnervating neurons inside the structures of Frankenhauser's ganglion [10]. Studies focusing on the double immunohistochemical staining of PCG perikarya in rats, cats and guinea pigs acknowledged the expression of vesicular acetylcholine transporter (VAChT) and choline acetyltransferase (ChAT) as markers of cholinergic neurons as well as noradrenaline (NA), tyrosine hydroxylase $(\mathrm{TH})$ and dopamine beta hydroxylase $(\mathrm{D} \beta \mathrm{H})$ as markers of the noradrenergic nerve cell population $[11,12]$. The coexistence of various substances in these types of neurons, including vasoactive intestinal polypeptide (VIP), neuropeptide Y (NPY), galanin (GAL), neuronal isoform of NO synthase (nNOS), somatostatin (SOM), galanin (GAL) and substance P (SP) has been confirmed by other authors $[9,13-18]$. Literature on the chemical coding of uterine-innervating populations of nervous cells in the porcine PCG is insufficient $[9,10]$. Moreover, there is a total lack of information regarding the impact of metritis/endometritis on the expression of any of these substances in either the noradrenergic or cholinergic neurons in PCG.

Since pigs are embryologically, anatomically and physiologically similar to human beings, their significance in any type of biomedical research, including studies on the reproductive system, is invaluable $[19,20]$. The authors intended to acquire data on the pig model which may help both animals and breeders by improving breeding indicators, survivability and profitability. In a broader aspect, the study may be valuable to women suffering from uterus inflammation, as it is hoped that these results will serve as a basis for the development of novel therapeutic agents, such as neurotransmitter analogues that can be administered to humans.

Literature describing the morphology and chemical coding of the uterine-perikarya in relation to the inflammation of the uterus is lacking. The available data show that endometritis in rats caused changed behavior as a probable response to visceral pain, as well as an augmented population of SP-immunoreactive neurons in the sensory ganglia (dorsal root ganglia; DRGs) [21, 22]. Three of the authors' published studies reported that, in gilts, endometritis has an impact on the uterussupplying neuronal populations. It was first reported that in Escherichia coli (E. coli)-evoked inflammation, the number of nerve fibers diminished, including noradrenergic fibers [23]. A subsequent article on the effect of uterine inflammation on sensory ganglia presented results showing decreasing numbers of perikarya in DRGs [24], whereas the most recent article described a drop in the total number of uterine supplying neurons in caudal mesenteric ganglion (CaMG) in response to the same disturbance [25]. Based on these results it may be hypothesized that metritis/endometritis affects the neurochemical properties of uterus-innervating neuronal cells in PCG in sexually mature gilts. Understanding the morphological and neurochemical changes of PCG uterine neurons in response to uterine inflammation may be important for the course and consequences of a pathological process. Therefore, the aim of the current study was to test this hypothesis by an examination of (1) the total number of uterine perikarya, as well as (2) determination of the number of cells expressing $\mathrm{D} \beta \mathrm{H}$ and/or VIP, NPY, SOM and nNOS in this ganglion.

\section{Results}

The number and distribution of uterine perikarya in the PCG

The most numerous concentrations of uterusinnervating PCG-labeled neurons were identified in the zone of the first 5 centimeters behind the portio vaginalis cervicis, gradually diminishing in the cranial direction. The total number of FB-positive neurons in the E. coli group was lower $(p<0.001)$ than in the control and saline groups ( $351 \pm 9.20$ vs. $588 \pm 16.70,610 \pm 13.24$, respectively). It is worth noting that in all groups left-side paracervical ganglia always had a lower $(p<0.001)$ amount of uterus-innervating perikarya than the rightside ganglia. Moreover, the decrease in the number of left-side neurons after bacterial administration was more significant vs. the control $(p<0.001)$ group than the 
saline $(p<0.01)$ group. Additionally, the right-side ganglia of the saline group presented a statistically more significant decrease in the number of the FB-positive neurons than the left-side formations of the same group in relation to the bacteria-treated population (right-side: $p<0.001$ vs. left-side: $p<0.01$ ).

The total number of perikarya, as well as the distinction into left and right-side populations of the PCG perikarya, is depicted in Fig. 1.

\section{The number of uterine-supplying neurons containing} DBH, SOM, VIP, NPY and nNOS in the PCG

In comparison to both control and saline groups, the number of $\mathrm{D} \beta \mathrm{H}+\mathrm{VIP}+$ uterine perikarya statistically significantly increased in the PCG of the bacteria treated gilts $(p<0.001)$ (Figs. $2 \mathrm{~A}$ and $3 \mathrm{~A}-\mathrm{H})$, whereas the $\mathrm{D} \beta \mathrm{H}-/ \mathrm{VIP}+$ population size was augmented $(p<$ 0.01 ) in relation to the saline group (Fig. 2A). Moreover, the numbers of $\mathrm{D} \beta \mathrm{H}+/ \mathrm{VIP}$ - in the E. coli group have noted a decrease $(p<0.05)$ when compared to both control and saline groups (Fig. 2A). The size of the $\mathrm{D} \beta \mathrm{H}-/ \mathrm{VIP}$ - population in E.coli-injected gilts diminished as well in comparison to control $(p<0.01)$ and saline $(p<0.001)$ groups of animals (Fig. 2A). In the PCG of E. coli-injected gilts, the number of $\mathrm{D} \beta \mathrm{H}+/ \mathrm{SOM}+$ neurons was higher than in the control $(p<0.01)$ and saline $(p<0.05)$ groups (Figs. 2B and 3 I-P). Furthermore, a rise $(p<0.01)$ was noted in the bacterial group' $\mathrm{D} \beta \mathrm{H}-/ \mathrm{SOM}+$ coded neurons when compared to other groups, whereas a decrease was present in the $\mathrm{D} \beta \mathrm{H}-/ \mathrm{SOM}$ - population in relation to both control $(p<0.001)$ and saline groups $(p<0.01)$ (Fig. 2B). E. coli treatment led to an increase in the population of the $\mathrm{D} \beta \mathrm{H}+/ \mathrm{NPY}+$ (Fig. $2 \mathrm{C}$, Fig. 4I-P) compared to other two groups (control group: $p<$ 0.05 , saline group: $p<0.01$ ), although the $\mathrm{D} \beta \mathrm{H}+\mathrm{NPY}-$ expressing population decreased $(p<0.05)$ its numbers in relation to the saline group (Fig. $2 \mathrm{C}$ ). Uterine inflammation also led to an increase in the number of $\mathrm{D} \beta \mathrm{H}+/ \mathrm{nNOS}+$ neurons in comparison with two other examined groups $(p<0.001)$ (Figs. $2 \mathrm{D}$ and $4 \mathrm{~A}-\mathrm{H})$, a decrease in $\mathrm{D} \beta \mathrm{H}+/ \mathrm{nNOS}$ - population (control group: $p<0.05$, saline group: $p<0.01)$, a rise $(p<0.05)$ in the size of $\mathrm{D} \beta \mathrm{H}-/ \mathrm{nNOS}+$ coded perikarya in relation to the control group, and evoked a decrease in the number of $\mathrm{D} \beta \mathrm{H}-/ \mathrm{nNOS}$ - neurons (control group: $p<$ 0.01) (Fig. 2D).

The numbers of uterine-supplying perikarya containing $\mathrm{D} \beta \mathrm{H}$ and/or VIP, SOM, NPY, nNOS, as well as those lacking the expression of all these neurotransmitters in the PCG of the control, saline-and bacteria treated gilts are presented in Fig. 2.

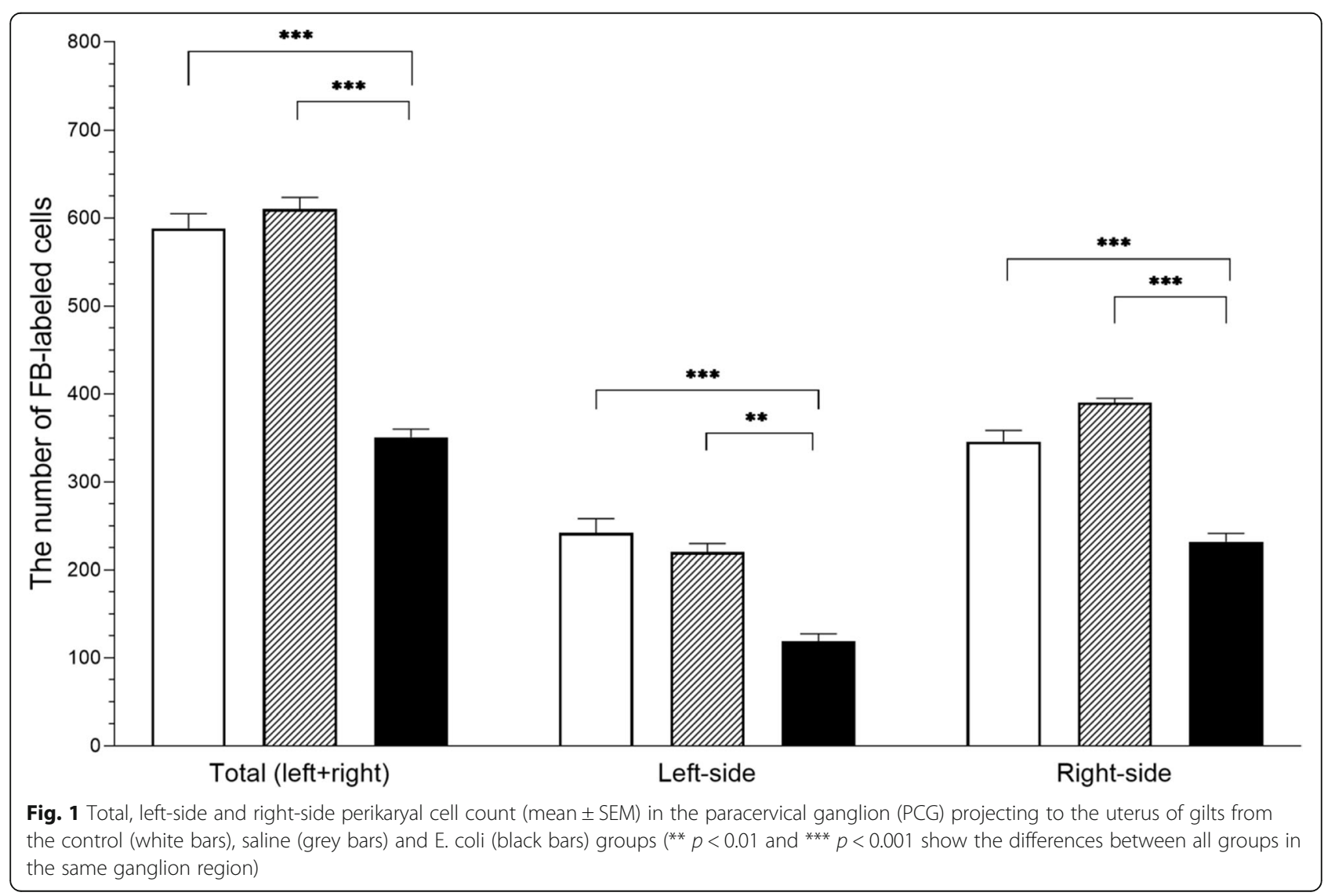



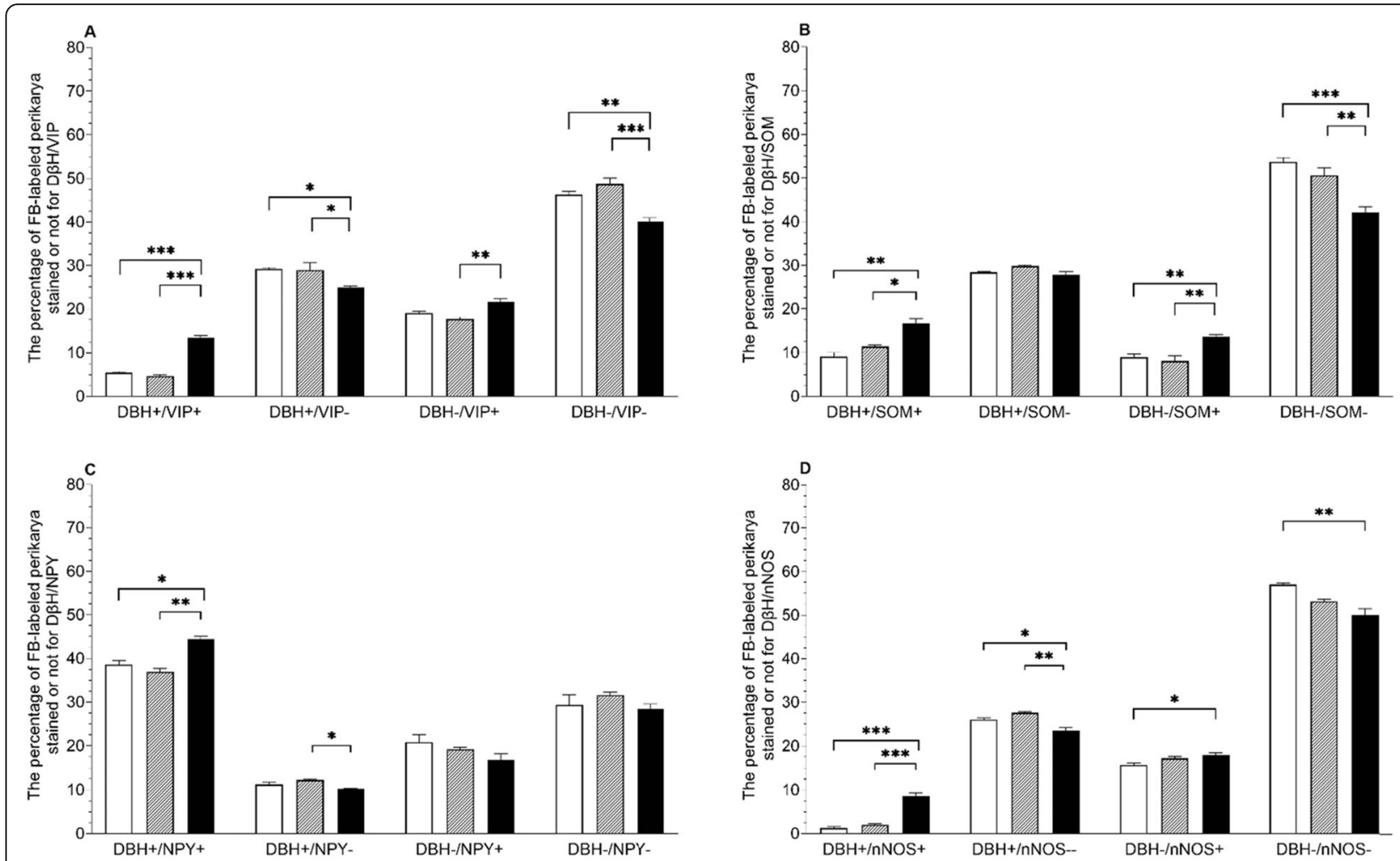

Fig. 2 The populations (expressed as percentages, mean \pm SEM) of uterine perikarya expressing dopamine- $\beta$-hydroxylase (D $\beta H)$ and/or vasoactive intestinal polypeptide (VIP) (A), D $\beta H$ and/or somatostatin (SOM) (B), D $\beta H$ and/or neuropeptide $Y(N P Y)(C)$ and D $3 H$ and/or neuronal isoform of nitric oxide synthase (nNOS) (D), as well as those without these substances in the PCG of gilts from the control (white bars), saline (grey bars) and E. coli (black bars) groups. Data are expressed as percentages of the total population of uterine perikarya stained for two substances in each group, accepted as $100 \%$. ${ }^{*} p<0.05,{ }^{* *} p<0.01$ and ${ }^{* *} p<0.001$ show differences between all groups for the same population of uterine perikaryal

\section{Discussion}

This is the first study to demonstrate alterations in the number, as well as the chemical coding of the PCG uterus-supplying neurons in sexually mature gilts with the bacteria-induced inflammation of uterus. Inoculation of the E. coli suspension was performed in the early luteal phase of the estrous cycle when the increasing level of immunosuppressive progesterone is conducive to the development of inflammation. Moreover, this action resulted in an incidence of a severe form of acute inflammation since $17 \beta$-estradiol (E2), uterine $\mathrm{PGF}_{2 \alpha}$ and LTs levels (which are considered to have the immunostimulating effect) are very low during this phase [26, 27]. On the microscopic level, such a form is diagnosed when the number of neutrophils is highly increased and luminal epithelium and/or glands are damaged [1]. Such a state was histopathologically proven and the results of such an examination were presented in a previous study by the authors [24]. It is worth noting that saline inoculation did not have a statistically significant impact on the total number of uterine-perikarya or any of the neurons immunoreactive to substances examined in this manuscript. These numbers were fairly similar, which is presented in the results.

The number of uterine perikarya in total was significantly decreased. Such an occurrence has a negative impact on uterus physiology and may imply that, due to innervation degradation, its immunity to inflammation, as well as adaptation capabilities and regulatory potential are impaired. The overall number of uterine neurons in the left-side PCGs was found to be lower than in the right-side in all animals. This finding is in an agreement with earlier studies [10] (for FB tracer injection into the cervical, paracervical and middle part of uterine horns) which found that the number of perikarya was always lower in the left side ganglia. Another significant fact is that since the decrease mentioned above was always more significant on the right-side in comparison to both groups of animals, we can speculate that the right-side neurons of PCG must play a more important role in the innervation of this organ. The fact that uterine inflammation has an impact on the functioning of the reproductive system, like ovaries where it may cause pathologic folliculogenesis, cysts formation or elongate 

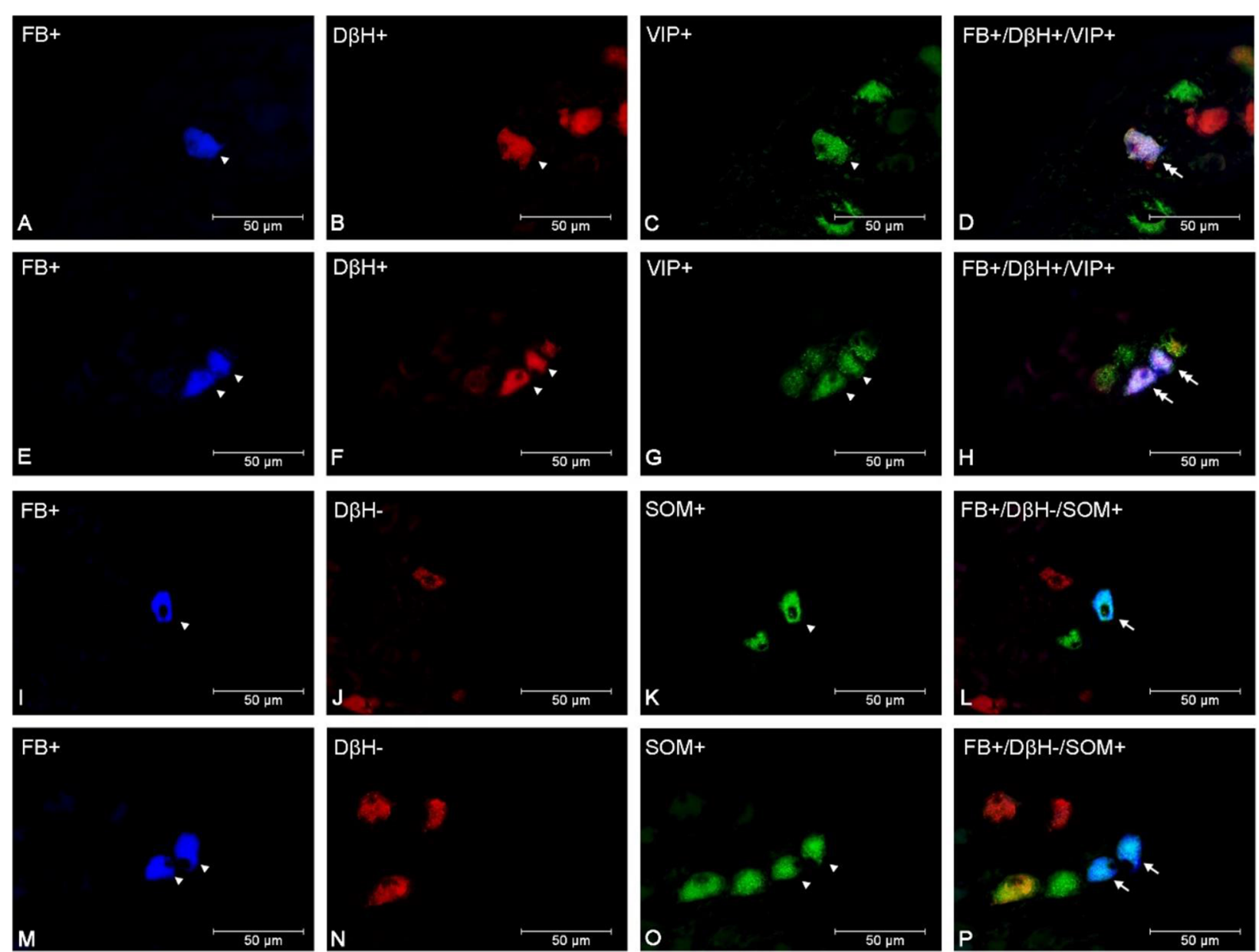

Fig. 3 Micrographs demonstrating the presence of $D \beta H(\mathbf{B}, \mathbf{F}, \mathbf{J}, \mathbf{N}), \mathrm{VIP}(\mathbf{C}, \mathbf{G})$ and SOM $(\mathbf{K}, \mathbf{O})$ in the PCG uterine perikarya of gilts from the control (A-D), saline (I-L) and E. coli (E-H, M-P) groups. The arrowhead indicates a Fast Blue (FB)-positive neuron, a perikaryon immunoreactive to $\mathrm{D} \beta \mathrm{H}$ and VIP and a perikaryon immunoreactive to SOM. The double arrow indicates an FB-positive uterine neuron expressing D $\mathrm{BH}$ and VIP. The arrow indicates an FB-positive perikaryon expressing SOM. The photographs $(\mathbf{D}, \mathbf{H}, \mathbf{L}, \mathbf{P})$ were made by digital superimposition of three color channels: FB-positive (blue), DBH-positive (red) and SOM- or VIP-positive (green). One D $\beta H$ and VIP immunoreactive uterine neuron is visible in the gilt of the control group (A-D). In the PCG of the E. coli group, an elevated number of perikarya expressing these substances are visible (E-H). One perikaryon expressing SOM, but not $\mathrm{D} \beta \mathrm{H}$, is present in the ganglion of the saline group (I-L). In the E. coli group, two perikarya expressing SOM are observed in the PCG (M-P)

the luteal phase is well known $[4,28,29]$. Therefore, as mentioned in the authors' previous articles on the current study [24, 25], the decrease in the numbers of uterine-perikarya may be treated as a consequence of both the endometritis and the decrease in the E2 level. This may also imply that an increase in the androstenedione level in pigs and cows results from it directly [29-31]. In the last decade, it was revealed that long-term E2 and testosterone administration decreases the number of ovary-innervating paracervical ganglion perikarya in the CaMG [32, 33], sympathetic chain ganglia (SChGs) [34], DRGs [35] and PCG as well $[36,37]$. In the available literature, the estrogen role has been determined to be neuroprotective, as it protects neuronal perikarya from fatal damage. Such action is possible due to their ability to activate intracellular signaling pathways, as well as estrogen receptors (ERs) [38, 39]. Such receptors can be commonly found in DRGs neurons innervating the uterus [40], porcine ovary neurons in the CaMG [32], as well as in sympathetic and parasympathetic neurons in the PCG of rats and pigs [36, 41]. Moreover, a decrease in the population of ER-immunoreactive perikarya has been reported as well as a simultaneous drop in the ovarian neuron numbers in PCG in response to a long-term E2 treatment [36]. On the other hand, long-term testosterone supplementation of gilts leads to an increase in the androgen receptorexpressing ovarian perikarya with a simultaneous decrease in the total number of these type of neurons 

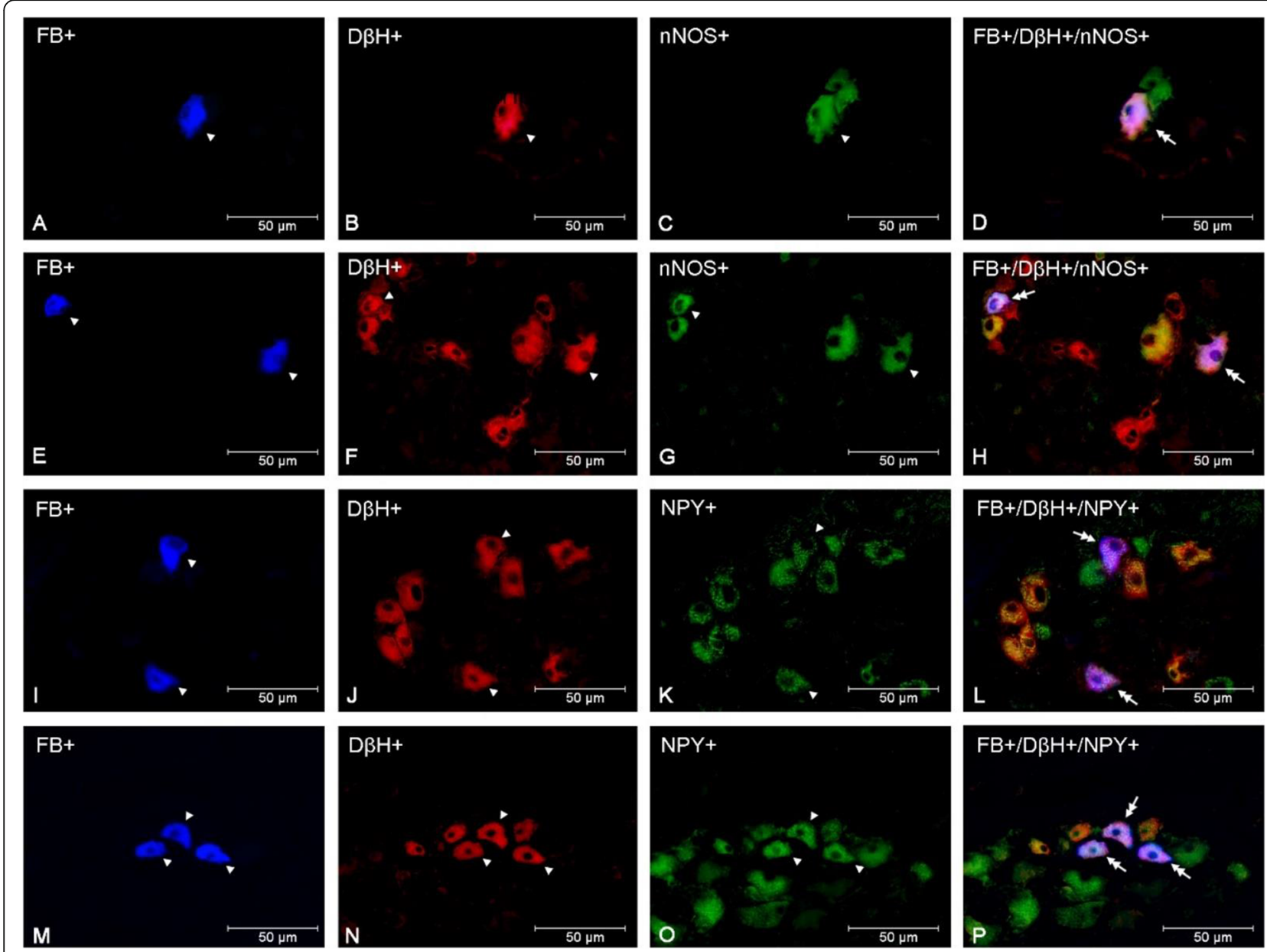

Fig. 4 Micrographs demonstrating the presence of $\mathrm{D} \beta H(\mathbf{B}, \mathbf{F}, \mathbf{J}, \mathbf{N})$, nNOS $(\mathbf{C}, \mathbf{G})$ and $N P Y(\mathbf{K}, \mathbf{O})$ in the PCG uterine perikarya of gilts from the control (A-D), saline (I-L) and E. coli (E-H, M-P) groups. The arrowhead indicates a Fast Blue (FB)-positive neuron, a perikaryon immunoreactive to $\mathrm{D} \beta \mathrm{H}$ and $\mathrm{nNOS} / \mathrm{NPY}$, a neuron immunoreactive to NPY, as well as an nNOS-immunoreactive perikaryon. The double arrow indicates an FBpositive uterine neuron expressing DBH and nNOS/NPY. The photographs were made by digital superimposition of three color channels: FBpositive (blue), D $B$ H-positive (red) and nNOS- or NPY-positive (green). One perikaryon expressing nNOS and DBH is present in the ganglion of the control group (A-D). In the E. coli group, two perikarya expressing these substances are observed in the PCG (E-H). Two D $3 H$ and NPY immunoreactive uterine neurons are visible in the gilt of the saline group (I-L). In the PCG of the E. coli group, an elevated number of perikarya expressing these substances are visible (M-P)

in the PCG [37]. The high probability of direct uterine inflammation impact on the seriously diminished numbers of uterine perikarya may be further supported by multiple reports of higher levels of proinflammatory cytokines in the course of uterine inflammation. These include substances such as TNF- $\alpha$, IL-1 $\beta$ or PGF $2 \alpha$ [4-6]. All mentioned cytokines are capable of the generation of free radicals while taking part in neuronal apoptosis [42]. This is why an alteration in uterine-perikarya in PCG can be connected to the above-mentioned facts, and could explain the similar values of estrogen and androgen receptors as well as inflammatory mediators receptors levels for the animals treated with bacterial inoculation. It is important to note that the decrease in PCGs neuronal numbers associated with steroid hormones and proinflammatory factors has not been sufficiently studied and requires more research.

Concerning changes in the chemical coding of uterineperikarya in PCG, there were no statistically significant alterations in $\mathrm{D} \beta \mathrm{H}_{-}$, VIP-, SOM-, nNOS- and NPYimmunoreactive neurons between the control and saline groups. This implies that either surgical actions and/or saline injections do not have any impact on the immunoreactivity of the examined perikarya.

The current study revealed a rise in the number of neuronal populations expressing $\mathrm{D} \beta \mathrm{H}$ and VIP, perikarya positive for $\mathrm{D} \beta \mathrm{H}$ and $\mathrm{SOM}, \mathrm{D} \beta \mathrm{H}$ and $\mathrm{NPY}$, as well as $\mathrm{D} \beta \mathrm{H}$ and nNOS. An increase was additionally found in neurons $\mathrm{D} \beta \mathrm{H}$-negative but VIP-positive, $\mathrm{D} \beta \mathrm{H}$ - 
negative but SOM-positive and $\mathrm{D} \beta \mathrm{H}$-negative but NOSimmunoreactive populations. In contrast to that, drops in the number of $\mathrm{D} \beta \mathrm{H}$-immunopositive but VIP-, NPYand nNOS-negative perikarya, as well as in neurons with no staining to any of the substances were presented. Similar to these results, in the authors' earlier study, a rise in large uterine-supplying, CaMG-located perikarya positive for $\mathrm{D} \beta \mathrm{H}$ and VIP, as well as $\mathrm{D} \beta \mathrm{H}$ and NPY, was reported [25]. To the contrary, other authors described the number of $\mathrm{D} \beta \mathrm{H}+/ \mathrm{VIP}+, \mathrm{D} \beta \mathrm{H}+/ \mathrm{NPY}+$ and $\mathrm{D} \beta \mathrm{H}+$ / $\mathrm{SOM}+$ ovary-innervating neurons both in CaMG and SChG decreasing in response to prolonged $17 \beta$-estradiol treatment in sexually mature gilts $[32,34]$. A decrease in $\mathrm{TH}, \mathrm{NPY}$ and VIP expressing CaMG-neurons was also presented for chemically induced colitis in pigs [43]. It is worth noting that the testosterone treatment caused an increase in the number of noradrenergic $\mathrm{D} \beta \mathrm{H}$ expressing ovarian neurons in immature gilts [37]. What is more, a recent study on the effects of Bisphenol A, which has a known impact on estrogen receptors, especially ER- $\alpha$, clearly shows that even small doses of this substance have a measurable impact on the number immunopositive nerve fibers located either in the right or left horn of the porcine uterine body. In this experiment, it is interesting that each uterine area noted a significant increase in populations of $\mathrm{D} \beta \mathrm{H}$ and VIPimmunopositive fibers, as well as those positively stained for $\mathrm{D} \beta \mathrm{H}$ and nNOS [44]. It is, of course, possible that some part of these are indeed perikaryal terminals of other sympathetic ganglia supplying the uterus, however, it is in line with the current study in which a population of $\mathrm{D} \beta \mathrm{H} / \mathrm{nNOS}$-immunoreactive perikarya appears. As these studies are the first to reveal changes in the chemical coding in the PCG of mature gilts, this suggests that such nNOS/D $\beta \mathrm{H}$-immunopositive neurons appear in animals after sexual maturation, whereas the rise in the E. coli-treated population may be a direct neuronal response to the uterine inflammation. Earlier studies revealed the existence of nNOS-immunoreactive perikarya in co-localization with VAChT [17]. However, a neuronal population immunoreactive to $\mathrm{TH}$ in colocalization with nNOS has been described in other studies on the immunohistochemical features of the PCG supplying the oviduct [45] although the animals used in that experiment were not sexually mature.

As mentioned earlier, a decrease in noradrenergic VIP-, SOM- and nNOS-negative perikarya was noted in the bacteria-treated group, which is testified by the results obtained in ovary-innervating neurons of SChGs and CaMG of sexually mature gilts treated with E2 [32, 34], as well as in CaMG uterinesupplying cells from the authors' previous studies [25]. Additionally, a drop in the numbers of $\mathrm{D} \beta \mathrm{H}$ negative and NPY positive perikarya similar to the drop found in the current study was also reported in one of the authors' recent studies [25]. Moreover, the non-sympathetic populations expressing VIP, SOM and $\mathrm{nNOS}$ in the $\mathrm{E}$. coli group increased in the current study. The mentioned alterations might indicate the disrupted variety of noradrenergic and nonsympathetic mechanisms. It has been proven that noradrenaline, which activates $\alpha$ - and/or $\beta$-adrenergic receptors and enhances PGs production, inhibits the contractility of the uterus, either in its physiological or pathological state [46-49]. Similarly, VIP and NPY also play a role in contractility regulation $[50,51]$. Moreover, VIP, best recognized due to its antiinflammatory functions, is also known for its neuroprotective capabilities, which include enhancing neuronal survivability in cells under pathological conditions, such as inflammations [52-54]. NO is also known for its neuroprotective role in both central and enteric nervous systems under optimal conditions $[18,55,56]$. NPY controls the blood flow in vessels and is invaluable due to its neuroprotective properties [57-60]. SOM, on the other hand, is able to adjust motility and cell proliferation in the endometrium [61]. The elevated numbers of VIP, NPY, SOM and nNOS expressing perikarya, either noradrenergic or not, may indicate an increasing demand to upregulate these valuable neurotransmitters in direct response to metritis/endometritis, in order to benefit from their neuroprotective and anti-inflammatory properties. In addition, some of the above-mentioned substances, like NPY and SOM, might have a supportive role in the process of exudate removal in the inflamed uterus due to their contractility-enhancing capabilities. In the practical aspect, the collected data may contribute to the development of new methods of prevention and treatment of uterine inflammations. It might also lead to the improvement of reproductive indicators, as well as fewer animals eliminated from breeding and increased production profitability.

\section{Conclusions}

In gilts, uterine inflammation due to E. coli resulted in alterations in numerical and neurochemical patterns of PCG uterine perikarya. Degradation of innervation might point to the fact that this organ's immunity, adaptation capabilities and regulatory potential are all significantly altered. Moreover, various changes in the number of sympathetic or non-sympathetic uterine neurons expressing different neurotransmitters imply that the inflamed state of the examined organ may have a strong impact on such neurons. The obtained results further assure that the pig model is still well-suited for research on the pathological states strictly related to animal breeding, as well as human beings, including studies on 
the reproductive system. These results may confirm the sufficient impact of the inflammation on the chemical coding of the involved neurons. Moreover, the expanded knowledge may be utilized to develop new therapeutic analogues of neurotransmitters to help the uterus to return to its normal functioning.

\section{Methods}

\section{Animals}

The described research was performed on 11 sexually mature, crossbred gilts acquired from the "Wronie" breeding farm located in Wronie, Poland. Each being in the age of 7-8 months and weighing $90-120 \mathrm{~kg}$. The animals showed signs of behavioral estrus, which was confirmed with the use of a tester boar. After unloading, all were randomly divided into 3 subgroups: A - E. coli group $(n=4), \mathrm{B}-$ saline group $(n=3)$ and $\mathrm{C}$ - control group $(n=4)$, each located in different pens. The animals had three days for adaptation, after which the experiment began. Gilts subjected for the research did not have any disturbances in reproductive processes and were kept in normal laboratory conditions inside the animal quarters of the Faculty of Veterinary Medicine of the University of Warmia and Mazury in Olsztyn, Poland. Feeding was standard for this species and age and water was available ad libitum. All animals were kept in $5 \mathrm{~m}^{2}$ individual pens, with $14.5 \pm 1.5 \mathrm{~h}$ of natural light during the day and $9.5 \pm 1.5$ at night. The temperature was kept at $18 \pm 2{ }^{\circ} \mathrm{C}$ in accordance with the instructions and agreement of the Local Ethical Committee in Olsztyn, Poland. Stress reaction connected to surgery and the time after was minimized in accordance with Consent no. 65/2015.

\section{Experimental procedures}

The procedures were as follows: on day 0 of the experiment (day 17 of the first studied estrous cycle) all animals received premedication consisting of atropine $(0.05 \mathrm{mg} / \mathrm{kg}$ of body weight $/ \mathrm{BW} /$, injected intramuscularly; Atropinum sulf. WZF, Warszawskie Zakłady Farmaceutyczne Polfa S.A., Poland), azaperone (2 mg/kg BW, injected intramuscularly Stresnil, Janssen Pharmaceutica, Beerse, Belgium) and ketamine hydrochloride $(10 \mathrm{mg} / \mathrm{kg}$ $\mathrm{BW}$, injected intravenously; Ketamina, Biowet, Puławy, Poland). General anesthesia was induced with the use of ketamine hydrochloride $(10 \mathrm{mg} / \mathrm{kg} \mathrm{BW}$, injected intravenously; Ketamina, Biowet, Puławy, Poland). It was then sustained with calculated doses of the same anesthetic $(1 \mathrm{mg} / \mathrm{kg} \mathrm{BW}$ applied after every five minutes, injected intravenously).

The subsequent abdominal incision was used to locate and expose the left and right uterine horns, after which a $5 \%$ aqua solution of $\mathrm{FB}$ retrograde fluorescent neuronal tracer (EMS-CHEMIE, GmbH, Germany) was thoroughly injected using a 26-gauge needle of a Hamilton syringe into the wall of both horns. Its tracing capabilities made the bodies of the uterine supplying neurons visible. The tracer was applied into three parts of horns - paracervical, middle and paraoviductal - each treated with 13 separate FB injections (with a $2 \mathrm{~cm}$ injection ring diameter, single injection volume $2 \mu \mathrm{L}$ and total $-26 \mu \mathrm{L}$ ). Due to FB leakage possibility the needle was left stationary for $60 \mathrm{~s}$ after each application. Injection areas were further rinsed with isotonic saline and wiped with gauze. The retrograde marker requires 4 weeks to reach the extrinsic sources of innervation.

With 28 days passed, all animals were anesthetized for the second time on the expected day 3 of the third studied estrous cycle using the same procedure as described earlier. Subsequent laparotomy allowed to inject either $50 \mathrm{~mL}$ of E. coli suspension (in case of the E. coli group; strain - O25:K23/a/:H1; 109-colony forming units/ml; National Veterinary Research Institute, Department of Microbiology, Puławy, Poland) or $50 \mathrm{~mL}$ of saline solution (for the saline group) into each uterine horn, whereas the control group received laparotomy only. On the expected 11th day of the third studied estrous cycle (8 days after laparotomies), all animals were euthanized by an overdose of an intravenously-injected ketamine hydrochloride. Then all animals were perfused with a $4 \%$ buffered paraformaldehyde via the ascending aorta and subjected for PCG collection along with the whole uterine cervix, as well as the ligamentum latum uteri. Moreover, parts of bladders were collected together with cervices to enhance spatial orientation. After collection, the tissues were postfixed by immersion in a fixative for $10 \mathrm{~min}$ and then washed with 0.1 M PB (pH 7.4) over the course of 2 days. Finally, these were stored at $4{ }^{\circ} \mathrm{C}$ in an $18 \%$ buffered sucrose solution ( $\mathrm{pH}$ 7.4) with an addition of $0.001 \%$ natrium azide. Until further procedures, the ganglia were kept at $-80{ }^{\circ} \mathrm{C}$. In order to determine the form of the inflammation, the fragments of uterine horns were fixed in a $4 \%$ paraformaldehyde solution $(\mathrm{pH} 7.4)$ for $24 \mathrm{~h}$, and the tissues were then washed in $0.1 \mathrm{M}$ phosphate buffered-saline (PBS, pH 7.4) and embedded in paraffin. The findings of the uteri histological assessment were published previously [24].

\section{Immunohistochemical analysis}

Collected uterine cervices were frozen together with PCG, cut in a cryostat (Frigocut, Reichert-Jung, Nussloch, Germany) into $14 \mu \mathrm{m}$ thick sections and mounted on chrome alun-coated slides. Using an Olympus BX51 microscope (Olympus, Poland) with an epi-illumination fluorescent microscopy module (V1 module, excitation filter $330-385 \mathrm{~nm}$, barrier filter $420 \mathrm{~nm}$ ), the presence of FB-positive uterine neurons was checked in the examined sections. All sections with FB-labeled neurons were 
subjected to immunohistochemical procedures, which consisted of a routine double-labeling immunofluorescence technique. After air-drying at room temperature for $45 \mathrm{~min}$. and rinsing in $0.1 \mathrm{M}$ phosphate-buffered saline (PBS; $\mathrm{pH}$ 7.4) three times for the duration of $10 \mathrm{~min}$. each, sections were incubated in a blocking buffer containing $10 \%$ of normal goat serum in $0.1 \mathrm{M}$ PBS, $0.1 \%$ donkey serum, $1 \%$ Triton X-100, $0.05 \%$ thimerosal and $0.01 \% \mathrm{NaN}_{3}$ for $60 \mathrm{~min}$. at room temperature in order to reduce non-specific staining background. Subsequently, after another wash in PBS (three times for $10 \mathrm{~min}$.), the sections were incubated overnight at room temperature with primary antisera against the $\mathrm{D} \beta \mathrm{H}$ and/ or SOM, VIP, nNOS, and NPY.

The following day sections were rinsed with PBS 5 times for $15 \mathrm{~min}$. and incubated with secondary antibodies (Alexa Fluor 488 and Alexa Fluor 546) suspended in PBS containing $0.25 \%$ BSA and $0.1 \%$ Trition X-100 for $1 \mathrm{~h}$ to show $\mathrm{D} \beta \mathrm{H} / \mathrm{SOM}, \mathrm{D} \beta \mathrm{H} / \mathrm{VIP}, \mathrm{D} \beta \mathrm{H} / \mathrm{NPY}$ and $\mathrm{D} \beta \mathrm{H} / \mathrm{nNOS}$ antibody combinations. The exact specifications of antibodies used are presented in Table 1. The sections were then rinsed with PBS three times for $5 \mathrm{~min}$. and covered with a glycerin solution containing DABCO (Sigma, USA). Standard controls, i.e. preabsorption for the neuropeptide antisera with appropriate antigen $(20 \mu \mathrm{g}$ of antigen $/ \mathrm{ml}$ diluted antiserum $)$ and the omission as well as the replacement of all primary antisera by nonimmune sera, were performed to test

Table 1 Antibodies used for immunostaining procedures

\begin{tabular}{|c|c|c|c|c|}
\hline \multicolumn{5}{|c|}{ Primary Antibodies } \\
\hline Antigen & Code & $\begin{array}{l}\text { Host } \\
\text { Species }\end{array}$ & Dilution & Supplier \\
\hline$D \beta H$ & AB1585 & rabbit & $1: 500$ & $\begin{array}{l}\text { Sigma-Aldrich, Saint Louis, } \\
\text { MO, USA }\end{array}$ \\
\hline VIP & $\begin{array}{l}\text { ABS } \\
023- \\
02\end{array}$ & mouse & $1: 1000$ & $\begin{array}{l}\text { ThermoFisher Scientific } \\
\text { Waltham, MA, USA }\end{array}$ \\
\hline SOM & $\begin{array}{l}8330- \\
0009\end{array}$ & rat & $1: 60$ & $\begin{array}{l}\text { Bio-Rad Laboratories, } \\
\text { Watford, United Kingdom }\end{array}$ \\
\hline NPY & $\begin{array}{l}\text { ABS } \\
028-08- \\
02\end{array}$ & mouse & $1: 1000$ & $\begin{array}{l}\text { ThermoFisher Scientific } \\
\text { Waltham, MA, USA }\end{array}$ \\
\hline nNOS & N218 & mouse & $1: 1000$ & $\begin{array}{l}\text { Sigma-Aldrich, Saint Louis, } \\
\text { MO, USA }\end{array}$ \\
\hline \multicolumn{5}{|c|}{ Secondary Antibodies } \\
\hline Reagent & Code & & Dilution & Supplier \\
\hline $\begin{array}{l}\text { Alexa Fluor } \\
488 \mathrm{~nm} \\
\text { donkey anti- } \\
\text { mouse lgG }\end{array}$ & A21202 & & $1: 1000$ & $\begin{array}{l}\text { ThermoFisher Scientific } \\
\text { Waltham, MA, USA }\end{array}$ \\
\hline $\begin{array}{l}\text { Alexa Fluor } \\
488 \text { nm } \\
\text { donkey anti- } \\
\text { mouse lgG }\end{array}$ & A11010 & & $1: 1000$ & $\begin{array}{l}\text { ThermoFisher Scientific } \\
\text { Waltham, MA, USA }\end{array}$ \\
\hline
\end{tabular}

immunohistochemical labelling. There was no fluorescence observed in any of these control stainings.

After staining, FB-labeled/double-immunostained neurons were further checked under a fluorescent microscope to count and analyze visible antibody combinations and then photographed with a digital monochromatic camera (Olympus XM 10) connected to a PC. All D $\beta \mathrm{H}-$, SOM-, VIP-, nNOS- and NPY-immunoreactive and/or all retrograde-labeled cell bodies were counted in every fourth section of the PCG. All uterine perikarya, aside from their diameters, were accepted into one size class. Differences were considered significant at $p<0.05$.

\section{Statistical analysis}

Data gained from PCGs of control $(n=4)$, saline $(n=3)$ and bacteria $(n=4)$-treated gilts, was averaged per total number of ganglion perikarya, the population of nerve cells in left- and right-side ganglia and perikarya with particular chemical coding for each group. Data are expressed as percentages of the total population of uterine perikarya stained for two substances in each group, accepted as $100 \%$. To calculate the standard error of mean $( \pm$ SEM), a one-way analysis of variance (ANOVA) followed by the Bonferroni test was used. All statistical analyses were performed using Statistica 13 software (StatSoft Inc., Tulsa, OK, United States). The differences were considered significant at $p<0.05$.

\section{Abbreviations}

PCG: Paracervical ganglion; D $\beta H$ : Dopamine- $\beta$-hydroxylase; NPY: Neuropeptide Y; SOM: Somatostatin; VIP: Vasoactive intestinal polypeptide; nNOS: Neuronal isoform of nitric oxide synthase; $\mathrm{E}$. coli: Escherichia coli; IL: Interleukins; NO: Nitric oxide; PG: Prostaglandin; LT: Leukotriene; VAChT: Vesicular acetylcholine transporter; ChAT: Choline acetyltransferase; NA: Noradrenaline; TH: Tyrosine hydroxylase; NANC: Nonadrenergic, non-cholinergic; GAL: Galanin; SP: Substance P; DRGs: Dorsal root ganglia; CaMG: Caudal mesenteric ganglion; FB: Fast-Blue; PBS: Phosphate buffer solution; ER: Estrogen receptor; TNF: Tumor necrosis factor

\section{Acknowledgements}

We thank Andrzej Pobiedziński and Joanna Kalinowska for their assistance.

\section{Authors' contributions}

Conceptualization, B.J. and B.M.; methodology, B.J.; formal analysis, B.M.; investigation, B.M. and B.J.; resources, B.J. and J.C.; data curation, B.M.; writing—original draft preparation, B.M.; writing—review and editing, B.J. and J.C.; visualization, B.M.; supervision, B.J. and J.C.; project administration, B.J.; funding acquisition, B.J. and J.C. All authors have read and agreed to the published version of the manuscript.

\section{Funding}

The research was funded by the National Science Center, Poland (grant No. 2014/15/B/NZ5/O3572). Project financially co-supported by the Ministry of Science and Higher Education in the range of the program entitled "Regional Initiative of Excellence" for the years 2019-2022, Project No. 010/RID/2018/19, amount of funding 12.000.000 PLN, which will cover the publication charges.

Availability of data and materials Not applicable. 


\section{Declarations}

\section{Ethics approval and consent to participate}

Procedures were carried out respecting the relevant Polish and EU legislation concerning Animal Protection and Welfare (Leg. Decree 26/2014 implementing the EU directive 2010/63/EU). Written informed consent to use the animals in our procedures was obtained from the owner. The procedures were approved and permission for specimens collection granted by the Local Ethics Committee of the University of Warmia and Mazury in Olsztyn (Consent no. 65/2015), affiliated to the National Ethics Commission for animal experimentation (Polish Ministry of Science and Higher Education).

\section{Consent for publication}

Not applicable.

\section{Competing interests}

The authors declare they have no competing interests.

Received: 24 February 2021 Accepted: 30 June 2021 Published online: 10 July 2021

\section{References}

1. De Winter PJJ, Verdonck M, De Kruif A, Devriese LA, Haesebrouck R. Bacterial endometritis and vaginal discharge in the sow: Prevalence of different bacterial species and experimental reproduction of the syndrome. Anim Reprod Sci. 1995;37:325-35.

2. Robertson J, Moll D, Saunders G. Chronic Staphylococcus aureus endometritis in a virgin gilt. Vet Rec. 2007;161:821-2.

3. Tummaruk P, Kesdangsakonwut S, Prapasarakul N, Kaeoket K. Endometritis in gilts: Reproductive data, bacterial culture, histopathology, and infiltration of immune cells in the endometrium. Comp Clin Pathol. 2010;19:575-84.

4. Jana B, Czarzasta J, Jaroszewski J. Synthesis of leukotrienes in porcine uteri with endometritis induced by infection with Escherichia coli. Reprod Fertil Dev. 2014;26:1007-16.

5. Gabler C, Drillich M, Fischer C, Holder C, Heuwieser W, Einspanier R. Endometrial expression of selected transcripts involved in prostaglandin synthesis in cows with endometritis. Theriogenology. 2009;71:993-1004.

6. Shao CY, Wang H, Meng X, Zhu JQ, Wu YQ, Li JJ. Characterization of the innate immune response in goats after intrauterine infusion of $E$. coli using histopathological, cytologic and molecular analyses. Theriogenology. 2012; 78:593-604.

7. Keast JR. Visualization and immunohistochemical characterization of sympathetic and parasympathetic neurons in the male rat major pelvic ganglion. Neuroscience. 1995;66:655-62.

8. Keast JR. The autonomic nerve supply of male sex organs - an important target of circulating androgens. Behav Brain Res. 1999;105:81-92.

9. Wasowicz K, Podlasz P, Czaja K, Łakomy M. Uterus-innervating neurones of paracervical ganglion in the pig: immunohistochemical characteristics. Folia Morphol. 2002;61(1):15-20.

10. Wasowicz K, Majewski M, Lakomy M. Distribution of neurons innervating the uterus of the pig. J Auton Nerv Syst. 1998;74:13-22.

11. Keast JR, Luckensmeyer GB, Schemann M. All pelvic neurons in male rats contain immunoreactivity for the synthetic enzymes of either noradrenaline or acetylcholine. Neurosci Lett. 1995;196:209-12.

12. Mitchell BS. Morphology and neurochemistry of the pelvic and paracervical ganglia. Histol Histopathol. 1993;8:761-73.

13. Alm P, Aluments J, Hakanson R, Helm G, Owman Ch, Sjöberg NO, et al. Vasoactive intestinal polypeptide nerves in the human female genital tract. Am J Obstet Gynecol. 1980;136:349-51.

14. Gu J, Polak JM, Su HC, Blank MA, Morrison JFB, Bloom SR. Demonstration of paracervical ganglion origin for the vasoactive intestinal polypeptide containing nerves of the rat uterus using retrograde tracing techniques combined with immunocytochemistry and denervation procedures. Neurosci Lett. 1984;51:377-82.

15. Inyama CO, Hacker GW, Gu J, Dahl D, Bloom SR, Polak JM. Cytochemical relationships in the paracervical ganglion (Frankenhauser) of rat studied by immunocytochemistry. Neurosci Lett. 1985;55:311-6.

16. Schultzberg M, Hökfelt T, Lundberg JM, Daalsgard CJ, Elfvin LG. Transmitter histochemistry of autonomic ganglia. In: Elfvin L-G, editor. Autonomic ganglia. Chichester: Wiley; 1983. pp. 205-33.
17. Podlasz P, Wasowicz K. Neurochemical characteristics of paracervical ganglion in the pig. Vet Med. 2008;53:135-46.

18. Burliński PJ, Gonkowski S, Całka J. Tetrodotoxin- and resiniferatoxin-induced changes in paracervical ganglion ChAT- and nNOS-IR neurons supplying the urinary bladder in female pigs. Acta Vet Hung. 2011;59:455-63.

19. Verma N, Rettenmeier AW, Schmitz-Spanke S. Recent advances in the use of Sus scrofa (pig) as a model system for proteomic studies. Proteomics. 2011; 11:776-93.

20. Swindle MM, Makin A, Herron AJ, Clubb FJ Jr, Frazier KS. Swine as models in biomedical research and toxicology testing. Proc Natl Acad Sci USA. 2012; 109:16612-7.

21. Wesselmann U, Czakanski PP, Affaitati G, Giamberardino MA. Uterine inflammation as a noxious visceral stimulus: Behavioral characterization in the rat. Neurosci Lett. 1998;246:73-6.

22. Li J, Micevych P, McDonald J, Rapkin A, Chaban V. Inflammation in the uterus induces phosphorylated extracellular signal-regulated kinase and substance $P$ immunoreactivity in dorsal root ganglia neurons innervating both uterus and colon in rats. J Neurosci Res. 2008;86:2746-52.

23. Meller K, Całka J, Palus K, Jana B. Inflammation-induced changes in expression of $\mathrm{D} \beta \mathrm{H}, \mathrm{SP}$ and $\mathrm{GAL}$ in the porcine uterine nerve fibres. The 4th Winter Workshop of the Society for Biology of Reproduction "Central and local Regulations of Reproductive Processes", Zakopane, Poland, 3-4 February 2016.

24. Bulc M, Całka J, Meller K, Jana B. Endometritis affects chemical coding of the dorsal root ganglia neurons supplying uterus in the sexually mature gilts. Res Vet Sci. 2019;124:417-25

25. Jana B, Całka J. Endometritis changes the neurochemical characteristics of the caudal mesenteric ganglion neurons supplying the gilt uterus. Animals. 2020;10:891.

26. De Winter PJJ, Verdonck M, De Kruif A, Coryn M, Deluyker HA, Devriese LA, et al. The relationship between the blood progesterone concentration at early metoestrus and uterine infection in the sow. Anim Reprod Sci. 1996; 41:51-9.

27. Lewis GS. Steroidal regulation of uterine immune defenses. Anim Reprod Sci. 2004;82-83:281-94.

28. Huszenica G, Fodor M, Gacs M, Kulcsar M, Dohmen MJW, Vamos M, et al. Uterine bacteriology, resumption of cyclic ovarian activity and fertility in postpartum cows kept in large-scale dairy herds. Reprod Domest Anim. 1999:34:237-45

29. Opsomer G, Gröhn YT, Hertl J, Coryn M, Deluyker H, de Kruif A. Risk factors for post-partum ovarian dysfunction in high producing dairy cows in Belgium: A field study. Theriogenology. 2000;53:841-57.

30. Peter AT, Bosu WTK. Effects of intrauterine infection on the function of the corpora lutea formed after first postpartum ovulations in dairy cows. Theriogenology. 1987;127:593-609.

31. Jana B, Kucharski J, Ziecik AJ. Effect of intrauterine infusion of Escherichia coli on hormonal patterns in gilts during the oestrous cycle. Reprod Nutr Dev. 2004:44(1):37-48.

32. Koszykowska M, Całka J, Szwajca P, Jana B. Long-term estradiol-17ß administration decreases the number of neurons in the caudal mesenteric ganglion innervating the ovary in sexually mature gilts. J Reprod Dev. 2011;57:62-71.

33. Jana B, Rytel L, Czarzasta J, Całka J. Reduction of the number of neurones in the caudal mesenteric ganglion innervating the ovary in sexually mature gilts following testosterone administration. J Neuroendocrinol. 2013;25:826-38.

34. Koszykowska M, Całka J, Gańko M, Jana B. Long-term estradiol-17ß administration reduces population of neurons in the sympathetic chain ganglia supplying the ovary in adult gilts. Exp Mol Pathol. 2011;91:353-61.

35. Jana B, Lata M, Bulc M, Całka J. Long term estradiol-17 $\beta$ administration changes population of the dorsal root ganglia neurons innervating the ovary in the sexually mature gilts. Neuropeptides. 2012;46:157-65.

36. Jana B, Palus K, Czarzasta J, Całka J. Long-term estradiol-17ß administration changes population of paracervical ganglion neurons supplying the ovary in adult gilts. J Mol Neurosci. 2013;50:424-33.

37. Jana B, Całka J, Bulc M, Czarzasta J. Long-term testosterone administration affects the number of paracervical ganglion ovary-projecting neurons in sexually mature gilts. Neurosci Res. 2014;83:89-96.

38. Green PS, Bishop J, Simpkins JW. Alpha-estradiol exerts neuroprotective effects on SK-N-SH cells. J Neurosci. 1997;15(17(2):511-5.

39. Cardona-Gómez GP, Mendez P, DonCarlos LL, Azcoitia I, Garcia-Segura LM. Interactions of estrogens and insulin-like growth factor-1 in the brain: Implications for neuroprotection. Brain Res Rev. 2001;37:320-34. 
40. Papka RE, Workley M, Usip S, Mowa CN, Fahrenkrug J. Expression of pituitary adenylate cyclase activating peptide in the uterine cervix, lumbosacral dorsal root ganglia and spinal cord of rats during pregnancy. Peptides. 2006:27:743-52.

41. Purves-Tyson TD, Arshi MS, Handelsman DJ, Cheng Y, Keast JR. Andro-gen and estrogen receptor mediated mechanisms of testosterone action in malerat pelvic autonomic ganglia. Neuroscience. 2007;148:92-104.

42. Hu S, Peterson PK, Chao CC. Cytokine-mediated neuronal apoptosis. Neurochem Int. 1997;30:427-31.

43. Wojtkiewicz J, Równiak M, Crayton R, Barczewska M, Bladowski M, Robak A, et al. Inflammation-induced changes in the chemical coding pattern of colon-projecting neurons in the inferior mesenteric ganglia of the pig. J Mol Neurosci. 2012;46:450-8.

44. Rytel L, Gonkowski S, Janowski T, Wojtkiewicz J, Pomianowski A. The effects of Bisphenol A (BPA) on sympathetic nerve fibers in the uterine wall of the domestic pig. Reprod Toxicol. 2019;84:39-48.

45. Czaja K, Wasowicz K, Klimczuk M, Podlasz P, Łakomy M. Distribution and immunohistochemical characterisation of paracervical neurons innervating the oviduct in the pig. Folia Morphol. 2001;60(3):205-11.

46. Kitazawa T, Nakagoshi K, Teraoka H, Taneike T. 5-HT(7) receptor and beta(2)adrenoceptor share in the inhibition of porcine uterine contractility in a muscle layer-dependent manner. Eur J Pharmacol. 2001;433:187-97.

47. Markiewicz W, Jaroszewski J. $\beta 2$-and $\beta 3$-adrenergic receptors stimulation relaxes porcine myometrium in the peri-implantation period. J Anim Sci. 2016;94:4611-8.

48. Skarzynski DJ, Uenoyama Y, Kotwica J, Okuda K. Noradrenaline stimulates the production of prostaglandin f2alpha in cultured bovine endometrial cells. Biol Reprod. 1999;60:277-82.

49. Quaas L, Zahradnik P. The effects of alpha- and beta-adrenergic stimulation on contractility and prostaglandin (prostaglandins E2 and F2a and 6-ketoprostaglandin $\mathrm{F} 1$ alpha) production of pregnant human myometrial strips. Am J Obstet Gynecol. 1985;152:852-6.

50. Bryman I, Norström A, Lindblom B, Dahlström A. Histochemical localization of vasoactive intestinal polypeptide and its influence on contractile activity in the non-pregnant and pregnant human cervix. Gynecol Obstet Invest. $1989 ; 28: 57-61$

51. Jana B, Całka J, Palus K. Inflammation changes the expression of neuropeptide $\mathrm{Y}$ receptors in the pig myometrium and their role in the uterine contractility. PLOS ONE. 2020;15(7):e0236044.

52. Delgado M, Ganea D. Cutting edge: is vasoactive intestinal peptide a type 2 cytokine? J Immunol. 2001;166(5):2907-12

53. Delgado M, Abad C, Martinez C, Juarranz MG, Arranz A, Gomariz RP, et al. Vasoactive intestinal peptide in the immune system: potential therapeutic role in inflammatory and autoimmune diseases. J Mol Med (Berl). 2002;80(1): $16-24$.

54. Abad C, Martinez Juarranz MG, Arranz A, Leceta J, Delgado M, Gomariz R. Therapeutic effects of vasoactive intestinal peptide in the trinitrobenzene sulfonic acid mice model of Crohn's disease. Gastroenterology. 2003;124(4): 961-71.

55. Rytel L, Całka J. Neuropeptide profile changes in sensory neurones after partial prepyloric resection in pigs. Ann Anat. 2016;206:48-56.

56. Calabrese V, Mancuso C, Calvani M, Rizzarelli E, Butterfield AD, Giuffrida Stella AM. Nitric oxide in the central nervous system: neuroprotection versus neurotoxicity. Nat Rev Neurosci. 2007;8(10):766-75.

57. Croce N, Ciotti MT, Gelfo F, Cortelli S, Federici G, Caltagirone C, et al. Neuropeptide $Y$ protects rat cortical neurons against $\beta$-amyloid toxicity and re-establishes synthesis and release of nerve growth factor. ACS Chem Neurosci. 2012;3(4):312-8.

58. Decressac M, Barker RA. Neuropeptide $Y$ and its role in CNS disease and repair. Exp Neurol. 2012;238:265-72.

59. Jovanovic $\mathrm{S}$, Grbovic L, Jovanovic A. Pregnancy is associated with altered response to neuropeptide $Y$ in uterine artery. Mol Hum Reprod. 2000;6:352-60.

60. Morris JL. Neuropeptide $Y$ inhibits relaxations of the guinea pig uterine artery produced by VIP. Peptides. 1990;11:381-6.

61. Annunziata M, Luque RM, Durán-Prado M, Baragli A, Grande C, Volante M, et al. Somatostatin and somatostatin analogues reduce PDGF-induced endometrial cell proliferation and motility. Hum Reprod. 2012;27:2117-29.

\section{Publisher's Note}

Springer Nature remains neutral with regard to jurisdictional claims in published maps and institutional affiliations.

\section{Ready to submit your research? Choose BMC and benefit from:}

- fast, convenient online submission

- thorough peer review by experienced researchers in your field

- rapid publication on acceptance

- support for research data, including large and complex data types

- gold Open Access which fosters wider collaboration and increased citations

- maximum visibility for your research: over $100 \mathrm{M}$ website views per year

At BMC, research is always in progress.

Learn more biomedcentral.com/submissions 